\title{
Percepção dos cozinheiros escolares sobre o processo de utilização de produtos orgânicos na alimentação escolar em municípios catarinenses
}

\author{
School lunch cooks' perception of the use of organic \\ foods in the school meals served in Santa \\ Catarina state, Southern Brazil
}

David Alejandro GONZÁLEZ-CHICA'

Arlete Catarina Tittoni CORSO ${ }^{1}$

Francieli CEMBRANEL'

Kátia Jakovljevic PUDLA ${ }^{1}$

Stella LEMKE $^{1}$

Bethsáida de Abreu Soares SCHMITZ

RE S U M O

\section{Objetivo}

Identificar o perfil dos cozinheiros escolares e avaliar a utilização, os benefícios e os possíveis fatores limitantes da introdução de alimentos orgânicos na alimentação escolar.

\section{Métodos}

Estudo transversal e exploratório incluindo os cozinheiros chefes de 242 escolas públicas municipais dos 52 municípios do estado de Santa Catarina que compraram alimentos orgânicos para a alimentação escolar em 2010. Os entrevistados foram questionados sobre a utilização de alimentos orgânicos, seus benefícios, as dificuldades e a capacitação recebida sobre esse tema. As prevalências e os IC 95\% foram calculados no software Stata 11.0.

\section{Resultados}

Dos 242 cozinheiros entrevistados, 97,4\% eram do sexo feminino, 86,6\% apresentavam 30 ou mais anos de idade e 47,9\% não cursaram o ensino médio ou superior. Entre esses, 9,4\% (IC95\% 6,1-13,9) desconheciam que a escola estava recebendo alimentos orgânicos. Entre aqueles que referiram usar alimentos orgânicos

${ }^{1}$ Universidade Federal de Santa Catarina, Departamento de Nutrição, Programa de Pós-Graduação em Nutrição. Campus Universitário, Trindade, 88040-900, Florianópolis, SC, Brasil. Correspondência para/Correspondence to: DA GONZÁLEZ-CHICA. E-mail: <david.epidemio@gmail.com>. 
408 | DA GONZÁLEZ-CHICA et al.

( $n=219), 42,7 \%$ (IC95\% 34,3-51,5) referiram presença diária desses alimentos no cardápio escolar. A qualidade dos alimentos no momento da entrega na escola foi considerada ótima/boa em 93,7\% dos casos. Quase $10,0 \%$ relataram dificuldades no uso desses alimentos, especialmente por problemas no recebimento/ armazenamento e baixa aceitação pelos alunos. A maioria percebeu benefícios no uso de orgânicos na alimentação escolar, tanto para os alunos (99,8\%) quanto para a comunidade $(100,0 \%)$.

\section{Conclusão}

O percentual de dificuldades encontrado pelos cozinheiros no uso dos alimentos orgânicos foi baixo, sendo positiva a avaliação quanto ao rendimento, a durabilidade, a quantidade de trabalho e a qualidade desses produtos em comparação aos não orgânicos. Os possíveis fatores limitantes poderiam ser corrigidos mediante melhoria na estrutura física das escolas, na logística de recebimento/estocagem desses alimentos, na capacitação direcionada dos cozinheiros e na sua maior integração nas políticas de alimentação escolar.

Termos de indexação: Alimentação escolar. Alimentos orgânicos. Culinária. Recursos humanos.

\section{A B S T R A C T}

\section{Objective}

This study investigated the profile of school cooks and assessed the use, benefits, and possible limitations associated with the introduction of organic foods in school meals.

\section{Methods}

This cross-sectional, exploratory study included the head cooks of 242 public municipal schools of 52 municipalities from the state of Santa Catarina that bought organic foods in 2010. The interviewees were asked about the use of organic foods, their benefits, the associated difficulties, and the training they were given on this subject. The software Stata 11.0 calculated the prevalences and 95\% confidence intervals.

\section{Results}

Of the 242 interviewed cooks, 97.4\% were females, $86.6 \%$ were aged 30 or more years, and $47.9 \%$ had not completed high school or higher education. Of these, $9.4 \%(95 \% \mathrm{Cl}=6.1-13.9)$ were not aware that the school was buying organic foods. Of the 219 cooks who used organic foods, 42.7\% (95\% Cl=34.3-51.5) reported that these foods were present every day in the school meals. The quality of these foods upon arrival at the school was considered great/good $93.7 \%$ of the time. Almost $10.0 \%$ of the interviewees reported difficulties associated with these foods, especially regarding delivery, storage, and low student acceptance. Most interviewees believed that these foods benefited the students (99.8\%) and the community (100.0\%).

\section{Conclusion}

Few cooks had difficulties using organic foods. The cooks found that their yield, shelf life, required work, and quality exceeded those of non-organic foods. The limitations could be eliminated by improving the layout of the schools, food delivery, food storage, cook training, and integration in school food policies.

Indexing terms: School feeding. Food organic. Cooking. Human resources.

\section{N T R O D U Ç Ã O}

A alimentação escolar no Brasil é um direito de todo aluno matriculado na educação básica de escolas públicas e filantrópicas, sendo dever do Estado garantir uma alimentação saudável e adequada'. O Programa Nacional de Alimentação Escolar (PNAE), a partir da Lei $n^{\circ}$ 11.947, de 16 de junho de 2009, garante o repasse de recursos financeiros e propõe diretrizes com o objetivo de contribuir para o crescimento e o desenvolvimento dos alunos, para a melhoria do rendimento escolar e para a formação de hábitos alimentares saudáveis ${ }^{1,2}$.

O emprego da alimentação saudável e adequada compreende o uso de alimentos variados e seguros, que respeitem a cultura, as tradições e os hábitos alimentares dos alunos, sendo recomendado o estímulo ao consumo de gêneros alimentícios diversificados e oriundos de produtores locais, preferencialmente da agricultura 
familiar e/ou de empreendedores familiares rurais ${ }^{1}$. Por esse motivo, do total de recursos financeiros repassados para o PNAE, no mínimo $30 \%$ devem ser utilizados na compra de gêneros provenientes desses produtores, devendo ser priorizada a compra dos alimentos orgânicos ${ }^{3}$. O cumprimento dessa recomendação é fundamental não apenas por estimular a permanência do pequeno produtor no campo, mas também para potencializar o consumo de frutas e hortaliças desde etapas precoces da vida, favorecendo um maior controle da obesidade e de outras doenças crônicas não transmissíveis, que nas últimas décadas vêm tendo um crescimento acelerado no Brasil $1{ }^{1,4}$.

Por sua vez, o estímulo à utilização de alimentos orgânicos é importante ao se considerar os múltiplos benefícios relacionados ao seu consumo: maior biodisponibilidade de micronutrientes, isenção de agrotóxicos, proteção para os produtores e para o meio ambiente, favorecimento da diversidade biológica e da manutenção da fertilidade dos solos ${ }^{5,6}$. No entanto, ao longo do processo de utilização dos alimentos orgânicos (desde sua produção até o consumo por parte dos escolares $\left.^{7}\right)$, existem algumas limitações que dificultam sua utilização, tais como o alto preço desses produtos e a falta de cumprimento de exigências higiênico-sanitárias ${ }^{8}$.

Nessa cadeia produção-consumo, os cozinheiros escolares são os executores finais das ações inseridas na política de alimentação escolar, visto que estão diretamente envolvidos na recepção e no preparo de todos os alimentos consumidos pelos alunos. Apesar da relevância dos cozinheiros na alimentação escolar e da relevância da utilização dos alimentos orgânicos, a informação disponível na literatura brasileira sobre a junção desses temas é escassa. Considerando esses aspectos, a finalidade do presente estudo foi identificar o perfil dos cozinheiros escolares, bem como caracterizar questões relacionadas ao uso dos alimentos, aos possíveis fatores limitantes e aos benefícios apontados por eles na utilização de alimentos orgânicos na alimentação escolar em municípios do estado de Santa Catarina.

\section{M É T O D O S}

Foi desenvolvido um estudo transversal e exploratório pelo Centro Colaborador em Alimentação e Nutrição do Escolar de Santa Catarina (CECANE/SC), executado em duas fases. Primeiramente, foi realizado um censo com as Secretarias de Educação de todos os municípios catarinenses, no qual os responsáveis pela alimentação escolar do município informaram sobre a utilização de alimentos provenientes da agricultura familiar, o percentual de recursos destinados para tal objetivo e se o município comprava alimentos orgânicos. O estado de Santa Catarina, localizado no sul do Brasil, está dividido em seis regiões diferentes (Norte, Sul, Oeste, Serrana, Vale do Itajaí e Grande Florianópolis), que incluem um total de 293 municípios. O índice de desenvolvimento humano do estado é 0,84 (segundo lugar no Brasil) e suas principais atividades econômicas são a prestação de serviços, a indústria e o comércio9,10.

Nessa primeira fase da pesquisa, foi utilizado um questionário eletrônico estruturado, o mesmo que foi encaminhado às Secretarias de Educação de todos os 293 municípios do estado de Santa Catarina. O questionário obteve retorno de aproximadamente $90,0 \%$ dos municípios $(n=264)$, dos quais $60,6 \%$ afirmaram comprar alimentos provenientes da agricultura familiar para a alimentação escolar e 23,1\% (n=54) referiram utilizar alimentos orgânicos para tal finalidade, distribuídos da seguinte forma: Norte 7/27, Sul $12 / 37$, Oeste $26 / 106$, Serrana $5 / 27$, Vale do Itajaí $3 / 48$ e Grande Florianópolis 1/1911.

Para a segunda etapa da pesquisa, foi selecionada uma amostra representativa das escolas existentes em todos os municípios que disseram comprar alimentos orgânicos para alimentação escolar em 2009. Inicialmente, foram identificadas as escolas públicas municipais, tanto urbanas como rurais, que ofereceram as modalidades de 
ensino infantil e/ou fundamental em 2009. Essa lista foi obtida do censo escolar disponível no site do Data Escola Brasi ${ }^{12}$, identificando-se 654 escolas atuantes nos 54 municípios que compraram orgânicos em 2009 (média de 12 escolas por município). Com a finalidade de maximizar o número de escolas na amostra, foi usada uma prevalência esperada de $50 \%$ para as diferentes informações a serem obtidas, um erro máximo tolerável de 5 pontos percentuais e um alfa de $5 \%$, totalizando uma amostra de 242 escolas. Considerando que todos os municípios que referiram comprar orgânicos seriam elegíveis para a pesquisa (não houve nenhum critério de exclusão no estudo) e que dois dos 54 municípios seriam selecionados para testar o instrumento de coleta de dados, seria necessário entrevistar uma média de cinco escolas por local para assim atingir o tamanho de amostra necessária. Em virtude de 15 municípios (29\%) apresentarem um número total de escolas menor que cinco, optou-se por escolher uma amostra de seis escolas nos demais locais. Dessa forma, em municípios com até cinco escolas, foram selecionadas todas as unidades educativas existentes, enquanto entre aqueles com maior número de escolas, foram selecionadas seis instituições, por meio de um processo de amostragem aleatória simples. Essas frações amostrais foram posteriormente consideradas no momento das análises.

Para a execução da segunda fase da pesquisa, foram realizadas no segundo semestre de 2010 visitas in loco nos municípios que afirmaram comprar alimentos orgânicos em 2009. As entrevistas foram realizadas com base em questionários estruturados, contendo blocos de perguntas fechadas e abertas em relação a variáveis sociodemográficas dos respondentes, à percepção sobre os benefícios, às dificuldades e às limitações pelo uso de alimentos orgânicos, cursos de capacitação recebidos sobre esse tema, características do processo de recebimento e preparação dos alimentos orgânicos e recomendações para melhoria do processo (questionários disponíveis a partir de solicitação dos autores). As entrevistas foram aplica- das por quatro entrevistadores com nível superior de educação (três nutricionistas e um agrônomo), os quais foram treinados antes da coleta de dados. Para realizar as entrevistas, cada município foi visitado por um dos entrevistadores entre os meses de setembro e dezembro de 2010, mediante agendamento com a nutricionista da Secretaria de Educação correspondente, ou com o responsável pela alimentação escolar do município, que agendou as visitas com cada uma das escolas selecionadas; visando reduzir a probabilidade de perdas, cada entrevistador permaneceu por até três dias laboráveis em cada município. Em cada uma das escolas, foram entrevistados todos os cozinheiros chefes ou o responsável principal pela preparação dos alimentos na escola.

Para descrição do perfil sociodemográfico dos cozinheiros chefes, foram investigados o sexo (masculino ou feminino), a idade (coletada como variável contínua e categorizada em faixas de 10 anos de idade) e a escolaridade em anos de estudo completos (categorizada posteriormente como 0-4, 5-8, 9-11 e 12 ou mais anos). Em relação ao processo de utilização dos alimentos orgânicos, foram obtidas informações sobre a periodicidade de entrega dos produtos na escola e a periodicidade de inclusão no cardápio dos escolares (diária, semanal, mensal ou anual), a qualidade dos alimentos no momento da entrega (ótima/ boa, razoável ou ruim/péssima) e a forma principal de armazenamento (geladeira, câmera fria, despensa ou outra). Os entrevistados também foram questionados sobre as possíveis diferenças encontradas no uso de alimentos orgânicos em comparação aos não orgânicos, considerando quatro variáveis: a durabilidade, o rendimento, a quantidade de trabalho e a quantidade consumida pelos alunos. As quatro variáveis sobre diferenças entre orgânicos e não orgânicos foram categorizadas de forma similar, de acordo com as seguintes categorias: melhorou com os orgânicos, permaneceu igual ou piorou. Os benefícios relacionados com o uso de orgânicos, tanto para os alunos (melhoria da saúde, melhoria no rendimento escolar e maior preocupação com a natureza) quanto para a comunidade (melhoria da 
economia regional, aumento da oferta de empregos, proteção do meio ambiente e melhoria da saúde dos produtores), foram coletados como variáveis dicotômicas (não/sim). A mesma categorização foi usada na coleta de informações sobre as dificuldades percebidas com uso dos orgânicos (problemas no recebimento, armazenamento, preparo dos alimentos e aceitação por parte dos alunos) e sobre a participação em cursos de capacitação nos últimos 12 meses (legislação, produção, transporte, armazenamento, preparação e benefícios dos orgânicos).

Os questionários foram digitados diretamente pelos entrevistadores no momento da entrevista em computadores portáteis, mediante formulário digital criado no software EpiData 3.1, o mesmo que gerou os bancos de dados correspondentes, os quais foram compactados posteriormente em arquivo único. As análises descritivas foram apresentadas como frequências absolutas e relativas, como os correspondentes Intervalos de Confiança de 95\% (IC95\%). Em todos os casos, foi considerado o peso amostral das escolas sele-cionadas (inverso da fração amostral; fração amostral, = número de escolas sorteadas/total de escolas no município), sendo utilizado em todas as análises o conjunto de comandos "survey" (svy) do STATA. As análises estatísticas foram desenvolvidas no software Stata 11.0 (Stata Corp., College Station, Estados Unidos).

Todos os participantes da pesquisa assinaram um Termo de Consentimento Livre e Esclarecido no momento da entrevista. O projeto de pesquisa foi aprovado em 31/08/2009 pelo Comitê de Ética em Pesquisa com Seres Humanos da Universidade Federal de Santa Catarina (Parecer $\left.n^{\circ} 1005 / 2010\right)$, de acordo com a Resolução 196/1996 do Conselho Nacional de Saúde do Ministério da Saúde ${ }^{13}$.

\section{RES U LTA D O S}

Nos 52 municípios do estado de Santa Catarina que referiram utilizar alimentos orgânicos na alimentação escolar, a taxa de resposta nas escolas selecionadas foi de $100,0 \%$, totalizando 242 cozinheiros escolares. A proporção de escolas visitadas por região foi maior na região Sul $(28,2 \%)$, seguida das regiões Norte $(26,9 \%)$, Oeste $(23,6 \%)$, Serrana $(11,8 \%)$, Vale do Itajaí $(8,3 \%)$ e Grande Florianópolis (1,2\%). A maioria das escolas pertencia a municípios de pequeno ou médio porte $(89,4 \%)$, enquanto $10,6 \%$ estavam localizadas em municípios de grande porte.

Quanto ao perfil dos entrevistados (Tabela 1), houve predomínio do sexo feminino $(97,4 \%)$, $86,6 \%$ apresentavam 30 ou mais anos de idade e $47,9 \%$ não cursaram o ensino médio ou superior.

Do total de entrevistados, 23 cozinheiros e desconheciam que a escola estava recebendo alimentos orgânicos para a alimentação escolar $(9,4 \%$; IC $95 \% 6,1-13,9)$. Entre aqueles que referiram usar alimentos orgânicos na preparação das refeições escolares ( $n=219$; Tabela 2), 78,6\% (IC95\% 69,7-85,3) indicaram que esses alimentos estiveram presentes no cardápio três ou mais vezes por semana.

A Tabela 2 mostra ainda que a periodicidade de entrega dos alimentos orgânicos na

Tabela 1. Perfil dos cozinheiros chefes $(n=242)$ dos municípios do Estado de Santa Catarina que utilizam alimentos orgânicos na alimentação escolar, 2010.

\begin{tabular}{lccc}
\hline Autor & $\mathrm{n}$ & $\%$ & $(\mathrm{IC} 95 \%)$ \\
\hline Sexo & & & \\
Feminino & 236 & 97,4 & $(92,7-99,1)$ \\
Masculino & 6 & 2,6 & $(0,9-7,3)$ \\
Idade & & & \\
20-29 anos & 33 & 13,5 & $(9,6-18,6)$ \\
30-39 anos & 67 & 27,9 & $(22,2-33,8)$ \\
40-49 anos & 77 & 31,9 & $(26,0-38,1)$ \\
50-59 anos & 65 & 26,8 & $(21,4-32,9)$ \\
Escolaridade* & & & \\
0-4 anos & 45 & 18,5 & $(14,0-24,2)$ \\
5-8 anos & 81 & 33,6 & $(27,7-40,0)$ \\
9-11 anos & 95 & 39,4 & $(33,2-45,9)$ \\
$\geq 2$ anos & 20 & 8,5 & $(5,1-12,5)$ \\
\hline
\end{tabular}

Nota: *Variável com dados ignorados para uma observação.

IC95\%: Intervalos de Confiança de 95\%. 
escola foi diária ou semanal em 81,5\% dos casos (IC95\% 74,8-86,7). A qualidade dos produtos orgânicos entregues nas escolas foi apontada como boa/ótima por mais de 90,0\% dos cozinheiros, e em quase $75,0 \%$ dos casos as principais formas de armazenamento mencionadas foram a geladeira ou a câmara fria.

Quanto às dificuldades percebidas que limitam o uso dos alimentos orgânicos na alimentação escolar, 10,1\% (IC95\% 6,4-14,6\%) dos entrevistados referiram algum tipo de dificuldade (dados não apresentados em tabelas), sendo que os entrevistados podiam apontar mais de um motivo. As principais dificuldades foram problema de armazenamento desses produtos (7,1\%), seguido pela baixa aceitação por parte dos alunos $(2,5 \%)$ e dificuldades no recebimento $(2,5 \%)$. A falta de capacitação e a dificuldade de preparo dos alimentos orgânicos foram indicadas como dificuldades por menos de 1,0\% dos cozinheiros. Quando questionados sobre sua própria aceita- bilidade em relação a esses produtos, todos responderam ter boa aceitação.

A Figura 1 apresenta as principais diferenças apontadas pelos cozinheiros que sabiam que a escola recebia esses alimentos no uso de alimentos orgânicos quando comparado ao uso dos não orgânicos ( $n=219)$. Tanto para a durabilidade dos alimentos $(n=178)$ quanto para a quantidade de trabalho, 20,0\% dos cozinheiros referiram que essas duas situações pioraram com a introdução dos alimentos orgânicos. Por sua vez, quase $65,0 \%$ dos cozinheiros referiram melhoria na durabilidade dos alimentos e 75,0\% não encontraram diferenças no volume de trabalho. Quase a metade dos entrevistados referiu melhoria no rendimento dos produtos e apenas 5,5\% apontaram que essa condição piorou. O item com piores resultados foi o consumo de frutas e vegetais por parte dos alunos, que apresentou redução segundo 58,0\% dos entrevistados.

Tabela 2. Uso de alimentos orgânicos na alimentação escolar, segundo a perspectiva dos cozinheiros escolares de municípios do estado de Santa Catarina, 2010.

\begin{tabular}{lccc}
\hline & $n$ & $\%$ & $($ IC95\%) \\
\hline Frequência no cardápio $(n=210)^{*}$ & & & $(34,3-51,5)$ \\
Diária & 90 & 42,7 & $(35,9-28,1)$ \\
3-4 vezes na semana & 75 & 35,9 & $(14,5-30,0)$ \\
1-2 vezes na semana & 44 & 21,2 & $(0,0-1,7)$ \\
Mensal & 1 & 0,2 & \\
Periodicidade de entrega na escola $(n=214)^{*}$ & & & $(0,4-3,6)$ \\
Diária & 3 & 1,3 & $(73,4-85,6)$ \\
Semanal & 171 & 80,2 & $(12,7-24,5)$ \\
Mensal & 38 & 17,9 & $(0,2-2,8)$ \\
Anual & 2 & 0,7 & $(85,4-97,4)$ \\
Qualidade quando chegam à escola $(n=212)^{*}$ & & & $(2,4-14,4)$ \\
Ótima/Boa & 198 & 93,7 & $(0,0-2,1)$ \\
Razoável & 13 & 6,1 & \\
Ruim/Péssima & 1 & 0,3 & $(62,4-80,1)$ \\
Armazenamento $(n=212)^{*}$ & & & $(0,5-11,2)$ \\
Geladeira & 153 & 72,1 & $(13,3-30,4)$ \\
Câmara fria & 5 & 2,5 & $(2,5-8,8)$ \\
Despensa & 44 & 20,6 & \\
Outras formas de armazenamento & 10 & 4,8 & \\
\hline
\end{tabular}

Nota: *Variável com dados ignorados para uma observação.

IC95\%: Intervalos de Confiança de 95\%. 


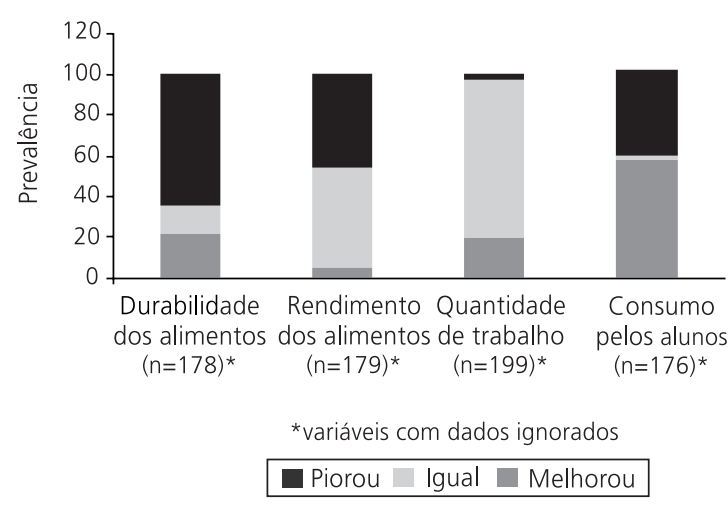

Figura 1. Diferenças encontradas com o uso de alimentos orgânicos em relação aos não orgânicos no preparo da alimentação escolar em municípios do estado de Santa Catarina, 2010. Respostas dos cozinheiros escolares que sabiam que a escola recebia estes alimentos $(n=219)$.

Tabela 3. Percepção dos cozinheiros escolares $(n=242)$ sobre os benefícios relacionados com o uso de alimentos orgânicos na alimentação escolar em municípios do estado de Santa Catarina, 2010.

\begin{tabular}{lcc}
\hline & $\mathrm{n}$ & $\begin{array}{c}\text { \% de respostas } \\
\text { afirmativas }\end{array}$ \\
\hline $\begin{array}{l}\text { Beneficios para os alunos com uso de } \\
\text { alimentos orgânicos }\end{array}$ & $241^{*}$ & 99,8 \\
Melhora saúde em geral & 242 & 100,0 \\
Melhora rendimento escolar & $235^{*}$ & 97,0 \\
Maior preocupação com a natureza & $235^{*}$ & 97,1 \\
Benefícios para a comunidade com & 242 & 100,0 \\
uso de alimentos orgânicos & & \\
Melhora economia regional & 242 & 100,0 \\
Aumenta oferta de empregos & $238^{*}$ & 98,2 \\
Protege meio ambiente & 242 & 100,0 \\
Melhora saúde de produtores & $240^{*}$ & 99,3 \\
\hline
\end{tabular}

Nota: "Variável com dados ignorados.

Ao serem questionados sobre cursos de atualização relacionados ao uso de alimentos orgânicos, e realizados a partir da promulgação da Lei $n^{\circ} 11.947 / 2009^{1}$, menos da metade dos cozinheiros (42,2\%; IC95\% 35,7-48,6) afirmou ter realizado algum curso desde aquele ano. Entre aqueles que realizaram esses cursos, o tema de legislação sobre o uso de alimentos orgânicos foi tratado em $58,1 \%$ das vezes. Outros temas tratados nesses cursos foram a produção de alimentos orgânicos $(71,8 \%)$, os cuidados com o trans- porte e o armazenamento desses produtos (84,2\%), os cuidados na preparação $(98,6 \%)$ e os benefícios para a saúde em geral $(95,2 \%)$.

A Tabela 3 apresenta a percepção sobre os benefícios que o consumo de alimentos orgânicos na alimentação escolar teria não apenas entre os alunos, mas também na comunidade. Da amostra, todos os cozinheiros referiram que o uso de alimentos orgânicos apresenta benefícios para a saúde dos alunos, e menos de 3\% referiram que o uso desses alimentos não aumenta o rendimento escolar e nem a conscientização ambiental. Da mesma forma, todos os entrevistados concordaram quanto ao benefício que o uso desses alimentos traz para a economia regional e para a proteção do meio ambiente, enquanto menos de $2 \%$ referiram que o uso desses alimentos não aumenta as fontes de emprego e nem melhora a saúde dos produtores.

\section{I S C U S S Ã O}

De conformidade com as evidências existentes na literatura científica, esta é a primeira pesquisa realizada no Brasil após a aprovação da Lei $n^{\circ} 11.947 / 2009$ e que teve como finalidade compreender as dificuldades e os benefícios na utilização dos alimentos orgânicos na alimentação escolar, sob a perspectiva dos cozinheiros chefes das cozinhas de escolas municipais. O estudo mostrou que o perfil predominante dos chefes de cozinha foi de indivíduos do sexo feminino, com idade entre 30-49 anos e de baixa escolaridade. O perfil encontrado estaria de acordo com as atividades requeridas para a função ${ }^{14}$, que favorece a inclusão de mulheres, sem que para tal função seja necessário um elevado grau de escolaridade. Uma pesquisa realizada em 2009, no município de Santa Fé (PR), por Colombo et al. ${ }^{15}$, que investigou 16 cozinheiros escolares, mostrou um perfil similar aos resultados do presente estudo quanto ao sexo (todos mulheres) e à escolaridade (mais da metade não havia concluído o ensino fundamental), mas, nesse caso, $80 \%$ das participantes 
se situavam na faixa etária acima de 50 anos de idade.

O perfil de baixa escolaridade entre os cozinheiros escolares reforça a necessidade de cursos de capacitação para esses profissionais, os quais não apenas deveriam estar direcionados para as boas práticas nutricionais e de controle sanitário, mas também no sentido de favorecer o uso dos alimentos orgânicos². Essa necessidade resulta mais evidente ao se considerar que a Lei $11.947 / 2009^{1}$ define que, dos recursos da alimentação escolar, 30\% devem ser destinados para a compra de produtos da agricultura familiar, com prioridade para a aquisição do gênero dos orgânicos. Mesmo assim, o presente estudo mostrou que menos da metade dos cozinheiros entrevistados afirmaram ter realizado algum curso desde 2009, e menos de dois terços referiram que o tema de legislação foi um dos tópicos abordados durante as capacitações. Associado a isto, vale ressaltar que aproximadamente $10 \%$ dos cozinheiros não conheciam que a escola estava recebendo produtos orgânicos para a alimentação escolar. O desconhecimento sobre esta temática por parte dos cozinheiros, assim como a falta de integração sobre as políticas de alimentação escolar que estão sendo executadas, representa um potencial limitante no processo de uso de alimentos orgânicos.

A capacitação insuficiente dos cozinheiros escolares tem sido apontada também por outros estudos. Uma pesquisa realizada em 2005 em Florianópolis (SC) por Lima \& Souza ${ }^{8}$ mostrou que nenhum dos cozinheiros escolares participou de programas formais de capacitação. Porém, o mesmo estudo mostrou que a realização de visitas aos fornecedores da alimentação orgânica foi vista como um fator que contribuiu para o conhecimento, a sensibilização e a motivação em relação à temática. Costa et al. ${ }^{16}$ ressaltam a importância do treinamento com o objetivo de formar profissionais mais críticos, autônomos e capazes para realizar sua função com competência. Carvalho et al. ${ }^{17}$, em pesquisa desenvolvida na Paraíba em 2005, destacam também a importância da formação de cozinheiros e revelam ausência de treinamentos sistemáticos e capacitação desses profissionais, sendo citada apenas a realização de cursos ou de palestras esporádicas. O mesmo estudo aponta que os cozinheiros consideram seu trabalho desvalorizado e parecem ter suas atividades norteadas por um conhecimento empírico adquirido por anos de prática. Leite et al. ${ }^{18}$, em estudo realizado no ano de 2007, em Salvador (BA), sobre uma proposta metodológica para formação de cozinheiros de escolas, revelaram que a realização periódica de cursos de capacitação foi sugerida pelos funcionários como uma estratégia benéfica para a realização das suas atividades. Dessa forma, a promoção de políticas de capacitação, valorização e integração desses funcionários pode constituir uma alternativa para melhorar o trabalho realizado e promover uma alimentação adequada aos alunos.

Em relação à utilização dos alimentos orgânicos, aproximadamente $40 \%$ dos entrevistados referiu que eles são incluídos no cardápio dos escolares com periodicidade diária, e em quase $80 \%$ das escolas a frequência foi de três ou mais vezes por semana. Embora não existam dados prévios à promulgação da Lei 11.947/2009¹, os nossos dados sugerem que houve avanços na inserção dos orgânicos na alimentação escolar, principalmente entre municípios de pequeno e médio porte. Em municípios de grande porte, no Brasil, foi localizada apenas uma pesquisa sobre este tema, realizada em 2005 em uma escola de ensino fundamental de Florianópolis (SC), que mostrou que os alimentos orgânicos estiveram presentes no cardápio escolar somente em 7 dos 21 dias avaliados ${ }^{8}$. Países como Itália, Finlân-dia, Dinamarca e Noruega mostram que é possível aumentar a cobertura e a frequência dos alimentos orgânicos oferecidos aos escolares ${ }^{19}$.

Chaves et al. ${ }^{20}$ analisaram a presença de alimentos regionais nos cardápios nas diversas regiões do País, e apontaram a Região Sul como a que, proporcionalmente, apresentou mais preparações regionais $(86,5 \%)$ comparada ao restan- 
te do país, que oscilou entre 38\% (Norte) e $84 \%$ (Norte e Sudeste). Embora esses autores não tenham avaliado a presença de orgânicos na alimentação escolar, esse achado reforça a necessidade da preocupação da inclusão desses itens na alimentação dos escolares.

Os autores Lima \& Souza ${ }^{8}$ relatam como fatores limitantes para a utilização de alimentos orgânicos na alimentação escolar o pequeno número de fornecedores certificados e o alto preço dos alimentos orgânicos, bem como problemas referentes à pontualidade da entrega, à solicitação e ao atendimento das compras, assim como à falta de cumprimento aos critérios higiênico-sanitários da embalagem e à rotulagem dos produtos. No presente estudo, o processo de distribuição dos alimentos orgânicos e a sua qualidade não foram limitantes para sua utilização. Apenas $2,5 \%$ dos cozinheiros chefes apontaram problemas no recebimento desses produtos, e, na maioria dos casos, eles foram classificados como de qualidade boa ou ótima. Assim, aparentemente, houve melhorias no processo de distribuição dos produtos após a Lei n 11.947/2009¹, o que poderia estar relacionado com o incremento no número de produtores rurais ${ }^{11}$.

Outro possível limitante no processo de distribuição seria a falta de estrutura física apropriada nas escolas para receber e armazenar esses produtos, que foi relatado por $10 \%$ dos entrevistados. Outros países que também oferecem alimentos orgânicos nas escolas precisaram encontrar diversos caminhos para superar essas dificuldades. Na Finlândia, por exemplo, na década de 1970, foram realizados grandes investimentos para melhorar a infraestrutura das cozinhas. Já em países como a Dinamarca e a Noruega, a solução aos problemas relacionados com a estrutura física das cozinhas foi a oferta de alimentos orgânicos embalados, como frutas e leite, embora exista a iniciativa de oferecer alimentos $\operatorname{cozidos}^{19}$.

De acordo com as respostas dos cozinheiros, outro fator relevante é a baixa aceitação por parte dos alunos. Mesmo que 2,5\% dos entrevistados tenham apontado este aspecto como uma dificuldade, em mais da metade dos casos os cozinheiros perceberam piora no consumo de frutas e vegetais quando os alimentos orgânicos foram introduzidos no cardápio. Vários fatores podem afetar o consumo dos alimentos oferecidos para os escolares neste programa, como características da família e da própria escola ${ }^{21}$. Embora as causas subjacentes para o menor consumo de alimentos orgânicos por parte dos escolares não tenham sido investigadas no presente estudo, a ação dos cozinheiros não parece ser um fator limitante: referiram ter capacitação suficiente para preparar esses alimentos, consideram benéfico o uso desses alimentos e não encontraram dificuldades na sua preparação. A durabilidade e o rendimento dos produtos foram apropriados, e não houve aumento na carga de trabalho. 0 estudo de Lima \& Souza ${ }^{8}$, realizado em 2005, mostrou também que os cozinheiros escolares não observaram diferenças quanto ao rendimento, à aparência e ao tempo de vida útil entre alimentos orgânicos e não orgânicos. Essas e outras qualidades dos alimentos orgânicos têm sido amplamente investigadas: em vários aspectos, esses produtos apresentam melhores características nutricionais do que os não orgânicos ${ }^{6,22}$.

Vale destacar que o uso de alimentos orgânicos na alimentação escolar vem de acordo com a Política Nacional de Segurança Alimentar e Nutricional (PNSAN), cuja proposta é regida pelos parâmetros do Sistema Nacional de Segurança Alimentar e Nutricional (SISAN) de acordo com a Lei $n^{\circ} 11.346 / 2006^{23}$. A política assegura uma alimentação adequada a toda população com práticas sustentáveis que respeitem o ambiente, a cultura, a economia e a sociedade ${ }^{24}$. Nesse sentido, o uso de alimentos orgânicos, especialmente de pequenos produtores e advindos da agricultura familiar, é uma alternativa que beneficia as crianças, os pequenos produtores e o meio ambiente.

Embora o presente estudo apresente como limitação a avaliação de uma parte dos municípios 
416 | DA GONZÁLEZ-CHICA et al.

no Estado de Santa Catarina, foram nele incluídos todos aqueles que compraram alimentos orgânicos em 2010. Da mesma forma, foi selecionada uma amostra representativa das escolas, e a taxa de resposta foi de $100 \%$. Assim, os resultados do presente estudo poderiam refletir a situação de outros municípios que estejam em processo de usar produtos orgânicos na alimentação escolar.

\section{CONCLUS Ã O}

Os cozinheiros escolares desempenham um papel central na utilização de produtos orgânicos na alimentação escolar. Apesar da boa percepção e da capacitação dos cozinheiros sobre os benefícios e a facilidade na utilização dos desses alimentos, algumas dificuldades foram citadas, envolvendo principalmente os processos de recebimento e estocagem desses produtos. Esses problemas poderiam ser corrigidos mediante melhoria na infraestrutura das cozinhas e de cursos de capacitação direcionados a melhorar o recebimento e a estocagem dos gêneros orgânicos. Por sua vez, novos estudos precisariam ser realizados para investigar os motivos subjacentes para a redução no consumo de frutas e verduras que aconteceu com a introdução dos alimentos orgânicos, situação que foi apontada por mais da metade dos cozinheiros.

Os resultados apresentados fornecem dados importantes que podem ajudar na inclusão dos alimentos orgânicos provenientes da agricultura familiar na alimentação escolar em todas as escolas do estado de Santa Catarina e apontam para a necessidade de ações governamentais conjuntas que procurem articular todos os atores envolvidos neste processo e que valorizem a utilização desses produtos na alimentação escolar.

\section{A G RADECIMENTOS}

Ao Fundo Nacional de Desenvolvimento da Educação - FNDE (Coordenação Geral do Programa Nacional de Alimentação Escolar) pelo financiamento desta pesquisa.

\section{COLABORADORES}

DA GONZÁLEZ-CHICA participou na coleta das informações, análise dos dados e redação do artigo. KJ PUDLA, S LEMKE e F CEMBRANEL participaram da análise dos dados e redação do artigo. ACT CORSO e BAS SCHMITZ participaram da coleta de dados e redação do artigo.

\section{REFERÊ NCIAS}

1. Brasil. Ministério da Educação. Lei $n^{\circ} 11.947$, de 16 de julho de 2009. Dispõe sobre o atendimento da alimentação escolar e do Programa Dinheiro Direto na Escola aos alunos da educação básica. Brasília: MEC; 2009 [acesso 2011 nov 3]. Disponível em: <http://www.planalto.gov.br/ccivil_03/ _ato2007-2010/2009/lei/l11947.htm>.

2. Weis B, Chaim NA, Belick W. Manual de gestão eficiente da merenda escolar. $3^{a}$ ed. São Paulo: Margraf; 2007.

3. Brasil. Ministério da Educação. Resolução CD/FNDE $n^{\circ} 38$, de 16 de julho de 2009. Dispõe sobre o atendimento da alimentação escolar aos alunos da educação básica no Programa Nacional de Alimentação Escolar - PNAE. Brasília: MEC; 2009 [acesso 2012 abr 1]. Disponível em: <http://www. fnde.gov.br/index. php/programas-alimentacaoescolar>.

4. Instituto Brasileiro de Geografia e Estatística. Antropometria e análise do estado nutricional de crianças, adolescentes e adultos no Brasil. Brasília: MEC; 2010 [acesso 2012 abr 1]. Disponível em: <http:// www.ibge.gov.br/home/estatistica/populacao/ condicaodevida/pof/2008_2009_encaa/pof_ 20082009_encaa.pdf>.

5. Brasil. Presidência da República. Lei n 10.831, de 23 de dezembro de 2003. Dispõe sobre a agricultura orgânica e dá outras providências. Brasília: Casa Civil; 2003 [acesso 2011 nov 4]. Disponível em: <http://www.planalto.gov.br/ccivil_03/LEIS/2003/ L10.831.htm>.

6. Bourn D, Prescott J. A comparasion of the nutritional value, sensory qualities, and food safety of organically and conventionally produced foods. Crit Rev Food Sci Nutr. 2002 [cited 2012 Mar 20]; 42(1):1-34. Available from: <http://www. tandfonline.com/doi/pdf/10.1080/10408690 290825439> doi: 10.1080/10408690290825439.

7. Buiainai AM, Batalha M. Cadeia produtiva de produtos orgânicos. Brasília: Ministério da Agricultura, Pecuária e Abastecimento; 2007 [acesso mar 20]. 
Disponível em: <http://www.ibraf.org.br/x_files/ Documentos/Cadeia_Produtiva_de_Produtos_ Org\%C3\%A2nicos_S\%C3\%A9rie_Agroneg\% C3\%B3cios_MAPA.pdf>.

8. Lima EE, Souza AA. Alimentos orgânicos na produção de refeições escolares: limites e possibilidades em uma escola pública em Florianópolis. Rev Nutr. 2011 [acesso 2011 nov 20]; 24(2):263-73. Disponível em: <http://www.scielo.br/rn>. doi: 10.15 90/S1415-52732011000200007.

9. Comissão Econômica para a América Latina e o Caribe, Programa das Nações Unidas para o Desenvolvimento, Organização Internacional do Trabalho. Emprego, desenvolvimento humano e trabalho decente: a experiência brasileira recente. Brasília: CEPAL; 2008 [acesso 2012 jan 25]. Disponível em: <http://www.pnud.org.br/publicacoes/emprego/ Paglniciais.pdf $>$.

10. Federação das Indústrias do Estado de Santa Catarina. Santa Catarina em dados: 2010. Florianópolis: FIESC; 2010 [acesso 2012 jan 20]. Disponível em: <http://www2.fiescnet.com.br/web/pt/site_ topo/pei/produtos/show/id/46>.

11. Centro Colaborador em Alimentação e Nutrição do Escolar de Santa Catarina. Relatório final do produto: "a disponibilidade de alimentos orgânicos da agricultura familiar para alimentação escolar em municípios do Estado de Santa Catarina". Florianópolis: CECANE SC; 2010.

12. Instituto Nacional de Estudos e Pesquisas Educacionais Anísio Teixeira. Data escola Brasil. Brasília: INEP; [s.d] [acesso 2011 nov 20]. Disponível em: $<$ http://www.dataescolabrasil.inep.gov.br/data EscolaBrasil>.

13. Brasil. Conselho Nacional de Saúde. Resolução $n^{\circ}$ 196, de 10 de outubro de 1996. Diretrizes e normas regulamentadoras de pesquisas envolvendo seres humanos. Brasília: CNS; 1996 [acesso 2013 jun 6]. Disponível em: <http://dtr2004.saude.gov.br/ susdeaz/legislacao/arquivo/Resolucao_196_ de_10_10_1996.pdf>.

14. Brasil. Ministério da Educação. Profuncionário: curso técnico de formação para os funcionários da educação. Brasília: MEC; 2006 [acesso 2012 jan 25]. Disponível em: <http://portal.mec.gov.br/seb/ arquivos/pdf/profunc/12_pol_aliment_escol.pdf>.

15. Colombo M, Oliveira KMP, Silva DLD. Conhecimento das merendeiras de Santa Fé, PR, sobre higiene e boas práticas de fabricação na produção de alimentos. Hig Alimentar. 2009 [acesso 2011 nov 20]; 23(170/171):39-46. Disponível em: <http:// bvs.panalimentos.org/local/File/Rev_HigAlim_v23_ n170_171_CONHECIMENTO_MERENDEIRAS_SANTAfePR_
HIG_BOAS_PRATICAS_FABRICACAO_PRODUCAO _ALIMENTOS.pdf>.

16. Costa EQ, Lima ES, Ribeiro VMB. O treinamento de merendeiras: análise do material instrucional do Instituto de Nutrição Annes Dias - Rio de Janeiro (1956-94). História Ciênc Saúde. 2002 [acesso 2011 nov 20]; 9(3):535-60. Disponível em: <http:// www. scielo.br/scielo.php?pid=S0104-59702002000300 004\&script=sci_arttext $>$. doi: 10.1590/S0104-59 702002000300004.

17. Carvalho AT, Muniz VM, Gomes JF, Samico I. Programa de alimentação escolar no município de João Pessoa - PB, Brasil: as merendeiras em foco. Interface. 2008 [acesso 2011 nov 20]; 12(27):823-34. Disponível em: <http://www.scielo.br/scielo.php? pid $=S 1414-32832008000400012 \&$ script $=$ sci_ arttext>. doi: 10.1590/S1414-3283200800040 0012.

18. Leite $C L$, Cardoso RCV, Góes JAW, Figueiredo KVNA, Silva EO, Bezerril MM, et al. Formação para merendeiras: uma proposta metodológica aplicada em escolas estaduais atendidas pelo programa nacional de alimentação escolar, em Salvador, Bahia. Rev Nutr. 2011 [acesso 2011 nov 20]; 24(2): 275-85. Disponível em: <http://www.scielo.br/rn>. doi: 10.1590/S1415-52732011000200008.

19. Nielsen T, Nölting B, Kristensen NH, Loes AK. A comparative study of the implementation of organic food in school meal systems in four European countries. Bioforsk Report. 2009 [cited 2011 Nov 20]; 4(145). Available from: <http://orgprints.org/ $16670 />$.

20. Chaves LV, Mendes PNR, Brito RR, Botelho RBA. O programa nacional de alimentação escolar como promotor de hábitos alimentares regionais. Rev Nutr. 2009 [acesso 2011 dez 3]; 22(6):857-66. Disponível em: <http://www.scielo.br/rn>. doi: 10.15 90/S1415-52732009000600007.

21. Sturion GL, Silva MV, Ometto AMH, Furtuoso MCO, Pipitone MAP. Fatores condicionantes da adesão dos alunos ao programa de alimentação escolar no Brasil. Rev Nutr. 2005 [acesso 2012 mar 20]; 18 (2):167-81. Disponível em: <http://www.scielo.br/ rn>. doi: 10.15 90/S1415-52732005000200001.

22. Matt $D$, Rembialkowska E, Luik A, Peetsmann E, Pehme S, Williams IH. Quality of organic vs. conventional food and effects on health. Tartu: Estonian University of Life Sciences; 2011 [cited 2011 Nov 20]. Available from: <http://orgprints. org/19504/1/Report_2011_\%281\%29.pdf>.

23. Brasil. Presidência da República. Lei n 11.346, de 15 de setembro de 2006. Cria o Sistema Nacional de Segurança Alimentar e Nutricional - SISAN com 
vistas em assegurar o direito humano à alimentação adequada e dá outras providências. Brasília: Casa Civil; 2006 [acesso 2013 jun 06]. Disponível em: <http://www.planalto.gov.br/ccivil_03/_ato20042006/2006/ lei/111346.htm>.

24. Brasil. Presidência da República. Decreto n 7.272, de 25 de agosto de 2010. Regulamenta a Lei no 11.346, de 15 de setembro de 2006, que cria o Sistema Nacional de Segurança Alimentar e Nutricional - SISAN com vistas a assegurar o direito humano à alimentação adequada, institui a Política
Nacional de Segurança Alimentar e Nutricional PNSAN, estabelece os parâmetros para a elaboração do Plano Nacional de Segurança Alimentar e Nutricional, e dá outras providências. Brasília: Casa Civil; 2010 [acesso 2012 nov 14]. Disponível em: $<$ HTTP://Www.planalto.gov.br/ccivil_03/_ato20072010/2010/decreto/ d7272.htm>.

Recebido em: 4/6/2012

Versão final em: 21/11/2012

Aprovado em: 27/2/2013 